\title{
Extraction of Hydroxyapatite from Fish Scales and Its Integration with Rice Husk for Ammonia Removal in Aquaculture Wastewater
}

\author{
Sofiah Hamzah ${ }^{1, *}$, Norhafiza Ilyana Yatim², Maslinda Alias ${ }^{1}$, Asmadi Ali ${ }^{1}$, \\ Nazaitulshila Rasit ${ }^{1}$, and Azzam Abuhabib ${ }^{1}$
}

${ }^{1}$ School of Ocean Engineering, Universiti Malaysia Terengganu, 21030 Kuala Nerus, Terengganu, Malaysia

${ }^{2}$ School Marine Science and Environment, Universiti Malaysia Terengganu, 21030 Kuala Nerus, Terengganu, Malaysia

\section{*Corresponding author:}

tel: $+609-6683971$

email:sofiah@umt.edu.my

Received: August 3, 2018

Accepted: December 13, 2018

DOI: $10.22146 / \mathrm{ijc} .40907$

\begin{abstract}
Aquaculture plays an important role in providing food and generate high income in many developing countries but the abundance of ammonia discharged from aquaculture wastewater gives the problem to the environment. This study focused on the extraction of hydroxyapatite (HAp) from fish scales and its modification with rice husk to produce bio-adsorbent for ammonia removal from aquaculture wastewater. The comparison has been made for the HAp preparation via microwave irradiation, alkaline heat treatment, and thermal decomposition method. X-ray Diffraction (XRD) and Fourier Transform Infrared Spectroscopy (FTIR) were used to analyze the surface chemistry and crystallinity of HAp, respectively. While the morphology of the HAp was observed under a Scanning Electron Microscope (SEM). Hydroxyapatite extracted via thermal decomposition method shows the best performance about 79\% of ammonia removal at 210 min contact time which selected for coating agent of rice husk (RH/HAp) and was successfully removed $84 \%$ at 60 min saturation time. The result shows thermal decomposition is the best technique to extract HAp from fish scales and its integration with rice husk exhibited a better performance of bio-adsorbent. The findings of this study provide useful fundamental knowledge and platform for the development and improvement of aquaculture wastewater treatment system in the future.
\end{abstract}

Keywords: hydroxyapatite; ammonia; aquaculture wastewater; rice husk; adsorbent

\section{- INTRODUCTION}

Aquaculture is among the fastest growing component of the agriculture sector in Malaysia and as this industry has expanded, so have concerns about water quality impacts from aquaculture effluent. This anxiety is understandable as seen in other countries, which face pollution problems for having ignored this problem. In intensive aquaculture system, organic enrichment comes primarily from uneaten food and fish feces, which is dispersed in the surrounding water. A report made by Randall and Tsui [1] has mentioned that the nutrient content of aquaculture effluents is often similar to domestic wastewater that is total suspended solid, biological oxygen demand, total phosphorus, ammonia, and nitrogen. The nutrients in fish feed can cause local algal blooms and lastly cause eutrophication. The common toxic pollutants are ammonia, nitrogen, phosphorus, pathogens and ammoniacal nitrogen $\left(\mathrm{NH}_{3}\right.$ and $\mathrm{NH}_{4}^{+}$).

The main source of ammonia in fish ponds is fish excretion and diffusion from the sediment when they decompose. The decomposition of this organic matter produces ammonia, which diffuses from the sediment into the water column. High ammonium concentration also will lead to a high free ammonia concentration under high $\mathrm{pH}$ condition, thus, it should be removed from wastewater before releasing it into natural water reservoirs [2]. 
Some conventional techniques applied to remove ammonia from wastewater either chemically or biologically cannot satisfy the increasing disposal need, or cannot solve the problem at an acceptable cost. Thus, there is a consistent need for an alternative separation technique for more efficient ammonia removal from water. This research studied a composite material from fish scales (HAp) and rice husk as an adsorbent for ammonia removal in aquaculture wastewater. Hydroxyapatite is a chemical substance related to the mineral component of bones and hard tissues in animals. The name 'apatite' describes a family of compound a similar structure which is a hexagonal system, space group, $\mathrm{P} 63 / \mathrm{m}$ in spite of a wide range of composition. Other than that, hydroxyapatites are also thermally unstable compound, decomposing at temperatures from about 800 to $1200{ }^{\circ} \mathrm{C}$ depending on its stoichiometry [3].

Moreover, several applications of hydroxyapatite were also interesting such as heavy metal adsorption, protein adsorption [4], chromatography, catalyst, photoelectric and others. Another medical application of hydroxyapatite has also been examined because hydroxyapatite is biocompatible, bioactive, non-toxic, non-inflammatory and also nonimmunogenic. Recent studies have proven the adsorption capability of hydroxyapatite (HAp), for instance, researchers Kongsri et al. [5], and Chen et al. [6] who proved that the hydroxyapatite can be efficient adsorbent in the wastewater purification and heavy metals removal. There are many natural sources for hydroxyapatite, which include human bone, bovine bone [7-8], coral [9], fish scale [10], and eggshell [11].

Several studies reported the preparation of HAp such as sol-gel processing [12], the precipitation technique [13], thermal decomposition and microwave irradiation [14]. For this purpose, parameters including composition and purity of the starting materials, $\mathrm{pH}$ and temperature of the solution must be controlled [15]. HAp extraction from natural resources such fish scales wastes is a good alternative to produce high-quality HAp and a good way to implement the concept of waste to wealth since fish scales is the main solid by-products of the fish processing industry. Abundant waste and residues rich in nutrient content can cause pollution and health problem if they are not properly treated since the fish wastes generated are 30 to $40 \%$ of the total production [16].

In certain condition, HAp could not be utilized at field condition due to the poor strength, brittle and less biocompatibility [17]. Thus, integration of this compound with other organic material such as rice husk can be believed to improve its mechanical strength, biocompatibility, and biodegradability. This modification also provides novel binding properties for potentially hazardous pollutant such as ammonia due to the presence of amino, silica and phosphate group of adsorbent. Rice husk also has high polar and hydrophilic nature and can serve as an excellent support for HAp during the adsorption process.

This work intended to compare the extraction methods of hydroxyapatite form fish scales using three techniques (microwave irradiation, alkaline heat treatment, and heat treatment) and the best structure of HAp is selected for modification in order to improve its efficiency in ammonia removal from aquaculture wastewater. The effect of adsorbent dosage and initial $\mathrm{pH}$ of ammonia solution were also studied to determine the best condition for ammonia removal using HAp/RH. Extraction of HAp from fish scales and its integration with rice husk has been a great option to produce adsorbent with lower cost and high efficiency for ammonia removal from aquaculture wastewater. This study can also provide a good idea for solid management in the aquaculture industry, reduce environmental pollution and make improvement of wastewater treatment in the aquaculture industry.

\section{- EXPERIMENTAL SECTION}

\section{Materials}

All the materials used in this research are of analytical grade. Hydrochloric acid $(\mathrm{HCl})$, Sodium hydroxide $(\mathrm{NaOH})$, orthophosphoric acid $\left(\mathrm{H}_{3} \mathrm{PO}_{4}\right)$, acetic acid $\left(\mathrm{C}_{2} \mathrm{H}_{4} \mathrm{O}_{2}\right)$, and ethanol $\left(\mathrm{C}_{2} \mathrm{H}_{6} \mathrm{O}\right)$ were purchased from Merck. Sodium hydrogen phosphate $\left(\mathrm{Na}_{2} \mathrm{HPO}_{4}\right)$ and Ethylenediaminetetraacetic (EDTA) were purchased from Sigma Aldrich. Fish scales from Tilapia species were obtained from a market in Terengganu, Malaysia. 


\section{Procedure}

\section{Extraction of HAp from fish scales}

In this study, three types of extraction method have been used to extract HAp from the fish scale (alkaline heat treatment, microwave irradiation, and thermal treatment). For alkaline heat treatment, the applied method was followed by Sukaimi et al. [8] and Shavandi et al. [14] with some modification. Tilapia fish scales is placed in an oven for $60 \mathrm{~min}$ after cleaning to remove water and moisture content of the scale. The scale was deproteinized via external washing with $0.1 \mathrm{M} \mathrm{HCl}$ and washed several times with distilled water. The remaining protein was treated with $5 \%$ (weight/volume) $\mathrm{NaOH}$, and heated at $80^{\circ} \mathrm{C}$ for $5 \mathrm{~h}$ with gentle stirring to eliminate all protein attaches to the scale. Fine white precipitates obtained were rinsed with distilled water and dried at $60{ }^{\circ} \mathrm{C}$ for $48 \mathrm{~h}$. Sodium hydroxide $(50 \% \mathrm{w} / \mathrm{v})$ was added into the treated scale, heated until $300{ }^{\circ} \mathrm{C}$ and kept 1 -h stirring. The obtained HAp powder was washed thoroughly with deionized water until the $\mathrm{pH}$ of rinsed solution become neutral. HAp produced was dried at $60{ }^{\circ} \mathrm{C}$ for $24 \mathrm{~h}$ prior to use in the oven.

For microwave irradiation method, the study by Shavandi et al. [14] has also referred by some modification. Fish scales were boiled in water for $30 \mathrm{~min}$ after cleaning and placed in an oven for $60 \mathrm{~min}$ to remove the water and moisture content of the scale. Dried fish scale is first heated in $300{ }^{\circ} \mathrm{C}$ at the heating rate of $3{ }^{\circ} \mathrm{C}$ $\mathrm{min}^{-1}$ for $1 \mathrm{~h}$. The temperature was increased at the rate of $10^{\circ} \mathrm{C} / \mathrm{min}$ and fixed between $900{ }^{\circ} \mathrm{C}$ and sintered for $3 \mathrm{~h}$. The black powder was slowly converted to snow white powder (calcium oxide) and then the furnace was cooled to the room temperature. The obtained calcium oxide was mixed with 0.1 M EDTA for the preparation of $0.1 \mathrm{M} \mathrm{Ca-}$ EDTA complex. $0.06 \mathrm{M} \mathrm{Na}_{2} \mathrm{HPO}_{4}(50 \mathrm{~mL})$ was then added dropwise to the Ca-EDTA complex and the liquid mixture was stirred for $15 \mathrm{~min}$. The $\mathrm{pH}$ value of the liquid mixture was kept at 13 . The mixtures were treated with microwave heating $(2.45 \mathrm{GHz}, 1100 \mathrm{~W})$ at $50 \%$ power capacity until the mixture dried. The obtained precipitate was washed few times with deionized water for $\mathrm{Na}$ and EDTA residuals removal, and then dried in a vacuum oven $\left(80^{\circ} \mathrm{C}\right.$ for $\left.6 \mathrm{~h}\right)$ for HAp powder formation.
The third method used was thermal treatment in which the cleaned scales were initially deproteinized through external washing with $1 \mathrm{~N} \mathrm{HCl}$ solution (2:1 volume/weight, water $\mathrm{HCl}$ ) for $24 \mathrm{~h}$ at room temperature $(30 \pm 2){ }^{\circ} \mathrm{C}$. Next, the deproteinized fish scales were washed thoroughly several times with distilled water. Remaining proteins of fish scales were treated with $1 \mathrm{~N}$ $\mathrm{NaOH}$ solution. The filtered fish scales were washed thoroughly with distilled water dried at $60^{\circ} \mathrm{C}$ in a hot air oven for several hours. Treated fish scales was calcined at temperature $1000{ }^{\circ} \mathrm{C}$ for hydroxyapatite formation. All HAp prepared via three different methods mentioned above were evaluated for ammonia removal efficiency from shrimp hatchery wastewater, Universiti Malaysia Terengganu.

\section{Modification of HAp with rice husk}

The best performance of HAp has been further modified with rice husk for comparison in their capability of ammonia removal. After cleaning, rice husk was dried in an oven at $105{ }^{\circ} \mathrm{C}$ for $2 \mathrm{~h}$. Dried rice husk was ground to form ash and sieved as to obtain a uniform particle size of $850 \mu \mathrm{m}$ to increase surface area. Sieved rice husk was treated with $1.0 \mathrm{M}$ Sodium Hydroxide $(\mathrm{NaOH})$ for surface area improvement. Then, rice husk was left on for $24 \mathrm{~h}$. Rice husk was washed in deionized water until $\mathrm{pH}=6$. Later, dried in an oven at $80{ }^{\circ} \mathrm{C}$ to remove moisture. The treated rice husk ( $1 \mathrm{~g}$ ) and HAp (1g) were immersed in 50\% of ethanol and stirred at $150 \mathrm{rpm}$ for $1 \mathrm{~h}$. The solution was then neutralized and it was filtered. Lastly, dried in an oven at $80^{\circ} \mathrm{C}$ to remove moisture.

\section{Characterization of HAp and HAp/RH}

Scanning electron microscopy (SEM) (JSM P/N HP475 model) was used to view surface morphology of the prepared adsorbent and all samples were coated with gold before transfer to the microscope. The elemental content of all adsorbents was also characterized using a wide angle X-ray diffractometer (XRD) using $18 \mathrm{~kW}$ $\mathrm{CuKa}$ radiation. The voltage was $45 \mathrm{kV}$ and the intensity

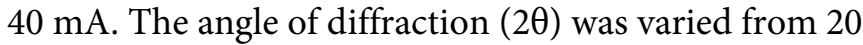
to 60 to identify any changes in crystal morphology and intermolecular distances between inter-segmental 
chains of the polymer, and the counting time was $1 \mathrm{~s}$ at each angle step. Surface chemistry of the prepared adsorbent was determined by Fourier to transform infrared spectroscopy equipped with attenuated total reflection (ATR-FTIR).

\section{Evaluation performance of HAp and adsorbent for ammonia removal}

The performance of the prepared adsorbent was evaluated based on their capability for ammonia removal in shrimp hatchery. Adsorption experiments were conducted to investigate the effects of different adsorbent and different parameters on ammonia removal from shrimp hatchery wastewater. The sample cell code is 2495402 which are $10 \mathrm{~mL}$ of the volume. For the first stage of the batch experiment, HAp extracted from three different methods (with the fixed dosage of $1.5 \mathrm{~g} / \mathrm{L}$ ) were mixed with $100 \mathrm{~mL}$ of shrimp hatchery wastewater in the conical flask and agitated in water bath shaker at $150 \mathrm{rpm}$ for 15 to $240 \mathrm{~min}$. The solution and residue were separated by the centrifugation method using Centrifuge (Model $5702 \mathrm{R}$ ) in $3000 \mathrm{rpm}$ for $10 \mathrm{~min}$. The suspension was filtered using Whatman filter no. 42 and the obtained filtrate solution was analyzed for ammonia content. The concentration of ammonia was determined using $\mathrm{HACH}$ method and detected with wavelength $655 \mathrm{~nm}$ at the range 0.01 to $0.50 \mathrm{mg} / \mathrm{L} \mathrm{NH}_{3}$ using a spectrophotometer. All experiments were done in triplicates. The mentioned techniques were also used for adsorption studies at the different adsorbent dosage (2-12 g/L) and initial $\mathrm{pH}(3-$ 9). Sodium hydroxide solution $(0.1 \mathrm{~N})$ and nitric acid solution $(0.1 \mathrm{~N})$ were used for $\mathrm{pH}$ adjustment. The efficiency of ammonia removal was calculated by Equation (1). The steps were repeated 3 times in order to get accurate data. Then the amount of adsorbed ammonia on the adsorbent was determined by calculated using the formula:

$\frac{\mathrm{C}_{\mathrm{i}}-\mathrm{C}_{0}}{\mathrm{C}_{\mathrm{i}}} \times 100 \%$

where, $C_{i}=$ initial concentration $(\mathrm{g} / \mathrm{L}) ; \mathrm{C}_{0}=$ concentration after using adsorbent $(\mathrm{g} / \mathrm{L})$

\section{- RESULTS AND DISCUSSION}

\section{Characterization of HAp from Fish Scales}

\section{XRD analysis}

The XRD patterns of commercial HAp (as control) and extracted HAp from fish scales with three different methods are shown in Fig. 1(a-d). All analysis had performed at $2 \theta\left(20\right.$ to $\left.60^{\circ}\right)$ with scan step $0.02^{\circ}$. For comparison purposes, commercial HAp had also characterized. Phase analysis revealed that all major peaks of HAp (the circle one) were present in all extracted HAp.

One of the major difference between the extraction method used was the final calcination used. According to Fig. 1, HAp obtained via alkaline heat treatment method shows a different pattern compared to commercial HAp but the major peaks of hydroxyapatite were still exists. In this method, calcination temperature used was only $300{ }^{\circ} \mathrm{C}$ (considered low calcination temperature) and thus the amorphous HAp powders obtained are expected to be more metabolically active than the fully developed crystalline hydroxyapatite structure which otherwise is not soluble in physiological environments [17]. According to Kongsri et al. [5], he stated that the broadened peaks of XRD data indicate low crystallinity while those of hydroxyapatite nanoparticle are sharper but still be amorphous. For Fig. 1 (c), the excellent peak is the indication for crystallinity is observed since HAp is calcined at a higher temperature $\left(1000{ }^{\circ} \mathrm{C}\right)$. According to Pham et al. [18], the lattice parameter of HAp will be increased with an increasing temperature and consequently increase the volume of the hexagon and so the changes in crystal size. According to the Fig. 1(d) well-resolved characteristic peak of highest intensity was obtained at a $2 \theta$ value of around $32^{\circ}$ due to complete crystallization of HAp powders extracted via thermal decomposition method. Impurities peaks decrease due to high calcine temperature used to overcome the activation energy, and shorten the annealing time [19] in order to transform calcite into HAp [20]. 

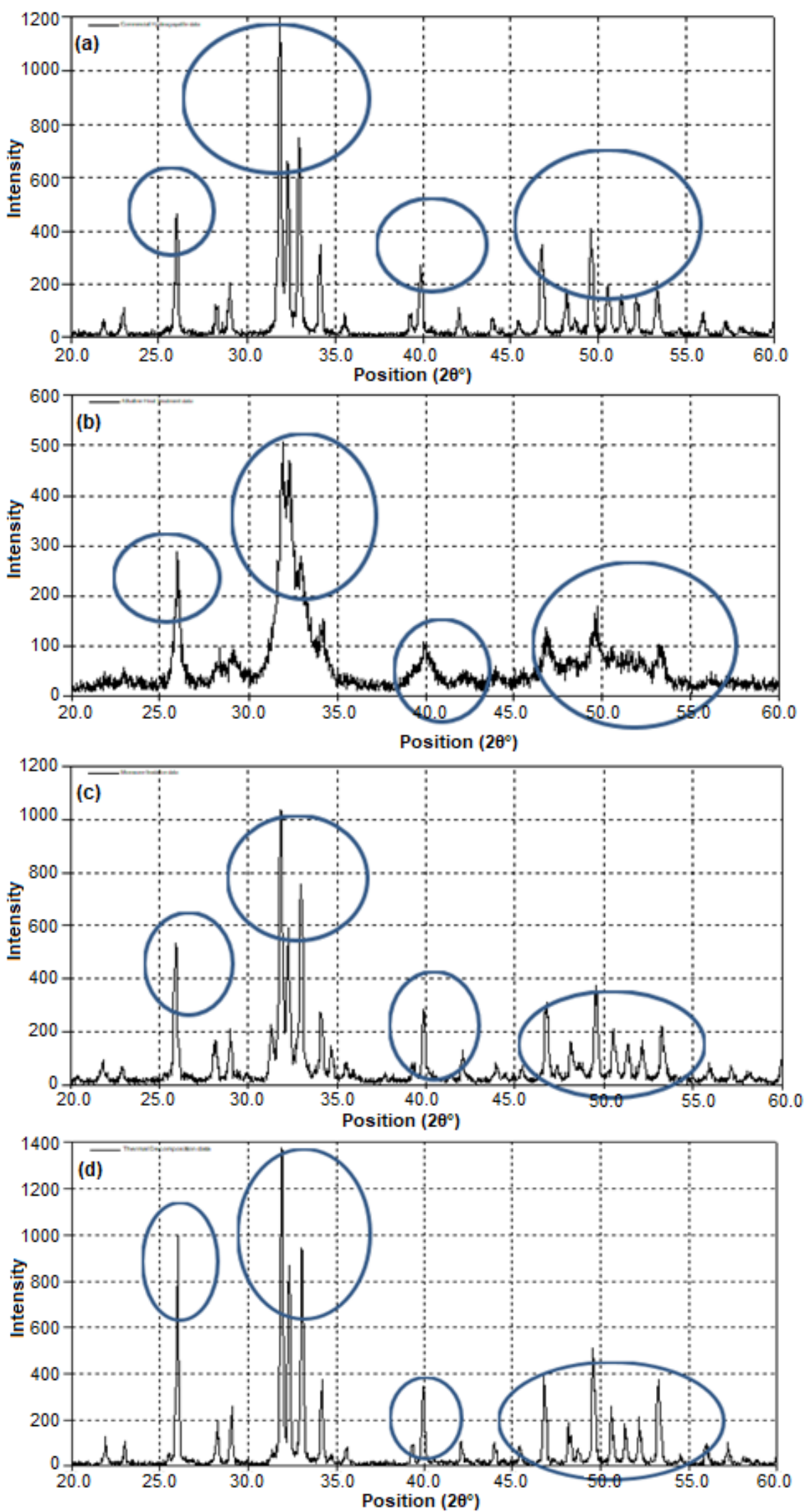

Fig 1. X-ray diffraction of hydroxyapatite of (a) commercial hydroxyapatite (b) HAp from alkaline heat treatment (c) HAp from microwave irradiation (d) HAp from thermal decomposition 


\section{ATR-FTIR analysis}

In this study, Fourier Transform Infrared (FTIR) Spectroscopy was employed to determine the existing functional groups of commercial hydroxyapatite (HAp) and extracted HAp from fish scale, as shown in Fig. 2. For all samples, the peak assigned to stretching mode of $\mathrm{OH}^{-}$
( 3200 to $3500 \mathrm{~cm}^{-1}$ ) is weak in the spectra of the products obtained and is not visible in the spectrum. This is also can be due to the overlap with the broad peak of the adsorbed water on HAp particles. The strong complex broadband at 1087 and $1022 \mathrm{~cm}^{-1}$ represent the stretching mode of $\mathrm{P}-\mathrm{O}$ vibration of $\mathrm{PO}_{4}$ group in Hap structure.
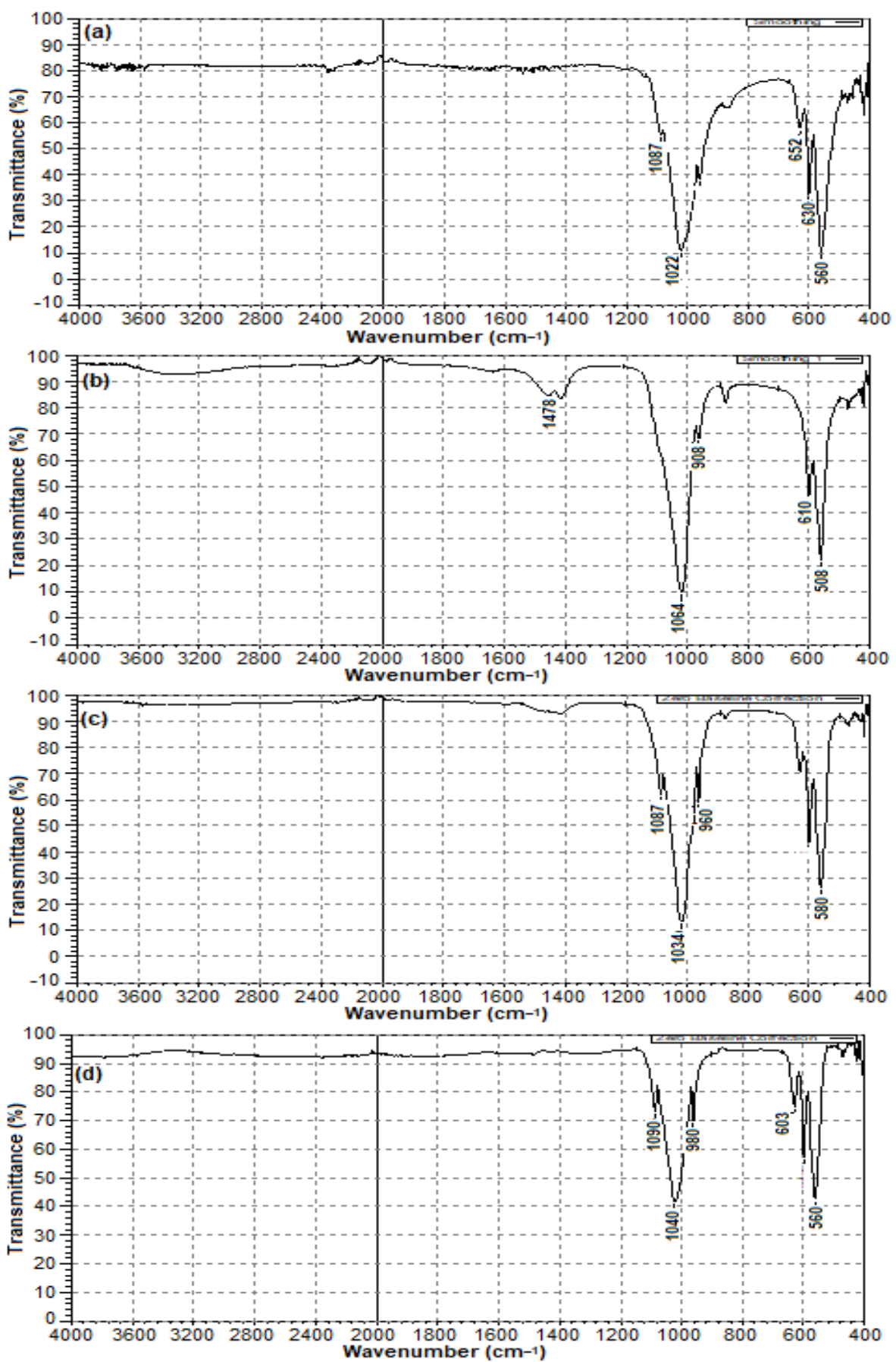

Fig 2. ATR-FTIR spectrum of (a) commercial hydroxyapatite (b) HAp from alkaline heat treatment (c) HAp from microwave irradiation (d) HAp from thermal decomposition 
The bands at 630 and $562 \mathrm{~cm}^{-1}$ in Fig. 2(a) and (d) are the bending modes of $\mathrm{P}_{4}{ }^{3-}$ [21]. Weak bands in the range of $1478 \mathrm{~cm}^{-1}$ in Fig. 2(c) indicated the presence of $\mathrm{CO}_{2}$ in the extracted HAp. These groups may have been adsorbed by the HAp samples from the atmosphere and replaced the $\mathrm{P}_{4}{ }^{3-}$ group in HAp during the HAp synthesis process [24]. No $\mathrm{C}-\mathrm{H}$ and $\mathrm{C}-\mathrm{N}$ peaks were found, which indicates that the obtained HAp was free from EDTA. However, asymmetric stretching of $\mathrm{v}_{1} \mathrm{PO}_{4}{ }^{2-}$ disappear from Fig. 2(b). This finding is supported by Venkatesan et al. [22] were at low temperature $\left(300\right.$ and $\left.400{ }^{\circ} \mathrm{C}\right)$, the peak attributed to phosphate group $\left(\mathrm{PO}_{4}{ }^{2-}\right)$ band does not appear and only appeared at temperature $500{ }^{\circ} \mathrm{C}$. This may be due to the removal of organic material from HAp and formation of HAp crystals. A sharp band at $1018 \mathrm{~cm}^{-1}$ is also observed in Fig. 2(b) and (c), which is typical of carbonate apatite, arising from the coupling between the symmetric stretching modes of $\mathrm{CO}_{3}{ }^{2-}$ with the stretching mode of $\mathrm{P}_{4}^{3-}$ [23]. Based on this finding, the extracted HAp was successful based on the existence of the main functional group of HAp, hydroxyl and phosphate group in each spectrum.

\section{Evaluation Performance of HAp for Ammonia Removal}

The performance of the extracted Hap by alkaline heat treatment, microwave irradiation, and thermal decomposition was evaluated for ammonia removal as shown as Fig. 3. The results obtained show that all adsorbent can perform as good adsorbent since it can remove more than $50 \%$ ammonia after $4 \mathrm{~h}$. Among the three extraction method used, HAp produced from thermal decomposition method can promote the highest ammonia removal for about $79 \%$. This might due to the high calcination temperature used for thermal treatment method $\left(1000^{\circ} \mathrm{C}\right)$, produced smaller and fine particles of Hap and more active site for the adsorption process. At this high temperature also, pure HAp was obtained at $2 \mathrm{~h}$ holding time while for the other two methods used, calcium carbonate was still present in 300 and $900^{\circ} \mathrm{C}$ with holding time of up to $3 \mathrm{~h}$ [14].

Extracted HAp via microwave irradiation present the lowest removal efficiency since in the microwave synthesis,

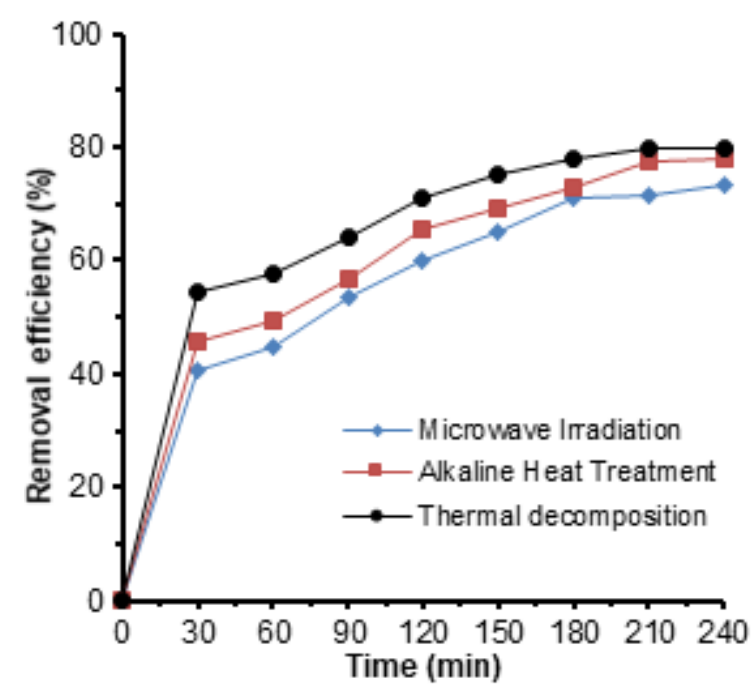

Fig 3. The performance of extracted HAp by microwave irradiation, alkaline heat treatment and thermal decomposition for ammonia removal (Adsorption condition: RT, dosage $1.5 \mathrm{~g} / \mathrm{L}, \mathrm{pH} 6$ )

heat is generated internally within the material, with a more uniform spatial temperature distribution and a higher heat transfer rate [24]. When the sample becomes the source of heating itself, the shape, size and the chemistry of the sample becomes very sensitive to heating [23].

\section{Effect of pH on Ammonia Removal}

The $\mathrm{pH}$ of wastewater is a significant parameter which influenced the adsorption process due to functional groups of both adsorbed molecules and adsorbent being affected by the concentration of hydrogen ions $\left(\mathrm{H}^{+}\right)$in the solution. This hydrogen ion involved in the adsorption process at the active sites of the adsorbent and mechanism for ammonia adsorption was known as surface complexation in which the particle surface is predominantly from positive charges in acidic solution, resulting in an increase of adsorption capacities by ligand-exchange [25]. This study also investigated the effect of $\mathrm{pH}$ of wastewater form shrimp hatchery for ammonia removal using extracted HAp via thermal decomposition and results has displayed in Fig. 4. There was always a pH-dependent between soluble ammonium ion $\left(\mathrm{NH}_{3}\right)$ and dissolved molecular ammonia $\left(\mathrm{NH}_{3}\right)$ in wastewater [26]. 


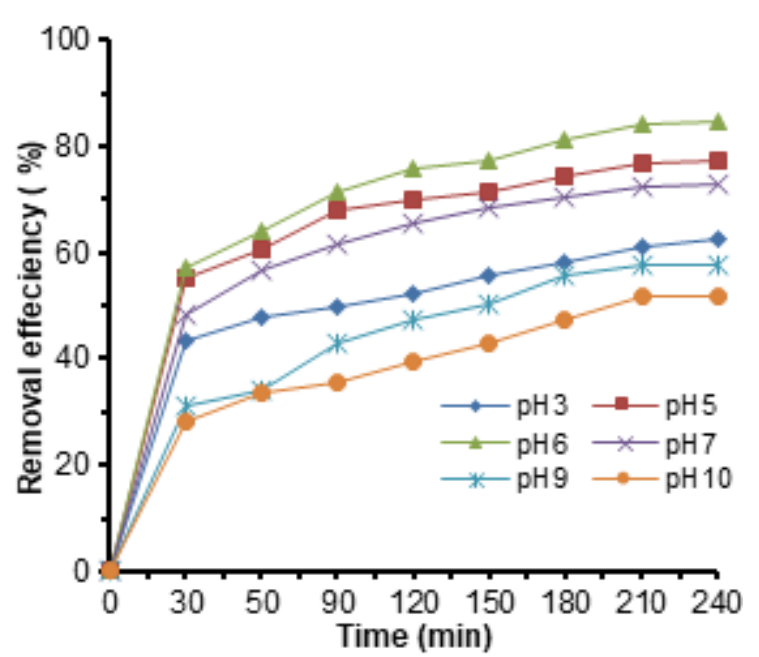

Fig 4. Effect of wastewater $\mathrm{pH}$ on the ammonia removal using extracted HAp by thermal decomposition (Adsorption condition: RT, dosage $1.5 \mathrm{~g} / \mathrm{L}$ )

According to Fig. 4 higher percentage of ammonia can be removed at the slightly acidic condition of wastewater ( $\mathrm{pH} \mathrm{6)}$. At saturation time around $210 \mathrm{~min}$, removal efficiency achieved was more than $70 \%$. This indicated that the positive form of hydroxyapatite was responsible for ammonia adsorption at this $\mathrm{pH}$ since the adsorbed ammonia is in the negatively charged form. The removal takes place by adsorption as well as precipitation, due to the formation of calcium ion [27]. This can be explained by the fact that, as the $\mathrm{pH}$ of the solution increased ( $\mathrm{pH} 3$ to $\mathrm{pH}$ ) the $\mathrm{OH}$ ions in the solution increase and form some complexes with Ammonia ions and thus form precipitate [28].

Very low ammonia removal observed when adsorption occurred at $\mathrm{pH} 3$ and this might due to the competition of $\mathrm{H}^{+}$and $\mathrm{NH}_{3}{ }^{+}$ions for the active sites in the adsorbent surface [27]. This might indicate a limited contribution of chemical adsorption that is caused by the unpaired electrons of ammonia at phosphate, hydroxide, and calcium functional groups of HAp [9]. The low biosorption capacity at $\mathrm{pH}$ values below 4 was attributed to the hydrogen ions that compete with ammonia ions on the sorption sites. In other words, at lower $\mathrm{pH}$, due to protonation of the binding sites resulting from a high concentration of protons, the negative charge intensity on the sites is reduced, resulting in the reduction or even inhibition of the binding of ammonia ions. Similar findings were reported by Mourabet et al. [29].

In alkaline condition ( $\mathrm{pH} 9$ and $\mathrm{pH} 10)$, the removal efficiency of ammonia was being the lowest one. At saturation time $210 \mathrm{~min}$, the removal was only 57 and $51 \%$, respectively and this low removal might due to the competition for adsorption sites between negatively charged ammonia [5,29-30]. In addition, the amount of adsorbed ammonia is limited by the repulsion of the electrostatic force between the negatively charged surface of the hydroxyapatite and ammonia [31].

\section{Integration of HAp and Rice Husk as an Efficient Adsorbent for Ammonia Removal}

\section{Morphology of adsorbent}

SEM micrograph of rice husk ash and $\mathrm{RH} / \mathrm{HAp}$ was illustrated in Fig. 5. Pre-treated $\mathrm{RH}$ with $\mathrm{NaOH}$ help to increase the surface area and heating for $2 \mathrm{~h}$ can cause the morphology obtained as solid fiber clumps with a rough surface. In RH/HAp adsorbent, the grain particle had increased and it might due to the sufficient time of integration and clumping the $\mathrm{RH}$ surface. The morphology of RH/HAp also shows the formation of the spherical structure is due to the sufficient synthesis of HAp which resulted in the proper composite formation. The morphology of highly agglomerated also may be due to the hydrogen bonding between the silica group on the surface of RH and phosphate group of HAp. The rough surface indicates the glassy silica component embedded with HAp.

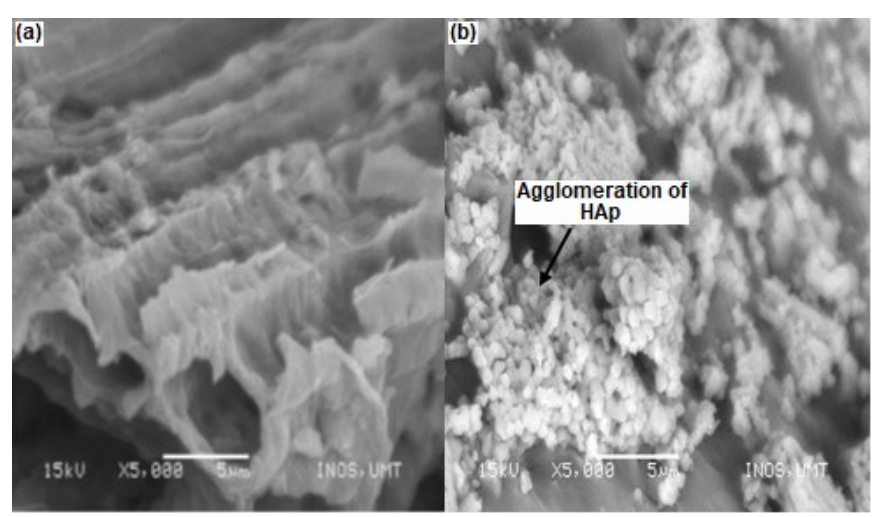

Fig 5. Morphology of (a) Rice husk ash and (b) RH/HAp 


\section{FTIR analysis}

FTIR spectrum of RH shows functional group from Si-O-Si $\left(1026 \mathrm{~cm}^{-1}\right), \mathrm{Si}-\mathrm{H}\left(800 \mathrm{~cm}^{-1}\right)$, carbonyl lactones $\left(1155 \mathrm{~cm}^{-1}\right)$ and $\mathrm{Si}-\mathrm{OH}\left(3000-3700 \mathrm{~cm}^{-1}\right.$ broadband) [32]. The spectra showed significant bands in the region centered about 1026, 800 and $459 \mathrm{~cm}^{-1}$ and these strong bonds were attributed to the existence of silica which accounts for a percentage in the rice husk.

In the FTIR of RH/HAp that shown in Fig. 6(b), a broadband of $630 \mathrm{~cm}^{-1}$ belongs to the vibration of hydroxyl $(\mathrm{OH})$ group and the band at 1024 and $962 \mathrm{~cm}^{-1}$ are the characterization of phosphate stretching vibration. The bands observed at 599, 565 and $470 \mathrm{~cm}^{-1}$ are due to the phosphate being in vibration. The peak of $\mathrm{PO}_{4}{ }^{3-}$ group shifted from 1087 to $1024 \mathrm{~cm}^{-1}$ due to interaction with rice husk [33]. From the FTIR analysis, all the functional group that presents in $\mathrm{RH}$ and HAp are present in RH/HAp. The FTIR data clearly shows that the adsorbent has been completely attaching to each other. This means that the process to integrate these two material (rice husk and HAp) was completely done.

\section{The Effect of contact time on ammonia removal}

HAp obtained through thermal decomposition method had used for the further study; to integrate HAp with rice husk ash, in order to improve the adsorption performance of rice husk ash and to reduce the usage of pure HAp. The result obtained was displayed in Fig. 7.

In this stage of the study, removal of ammonia using the prepared adsorbent achieved its saturation time around $60 \mathrm{~min}$ contact time. This results proved that integration of HAp with rice husk can be a better adsorbent due to shortening of reaction time. A better
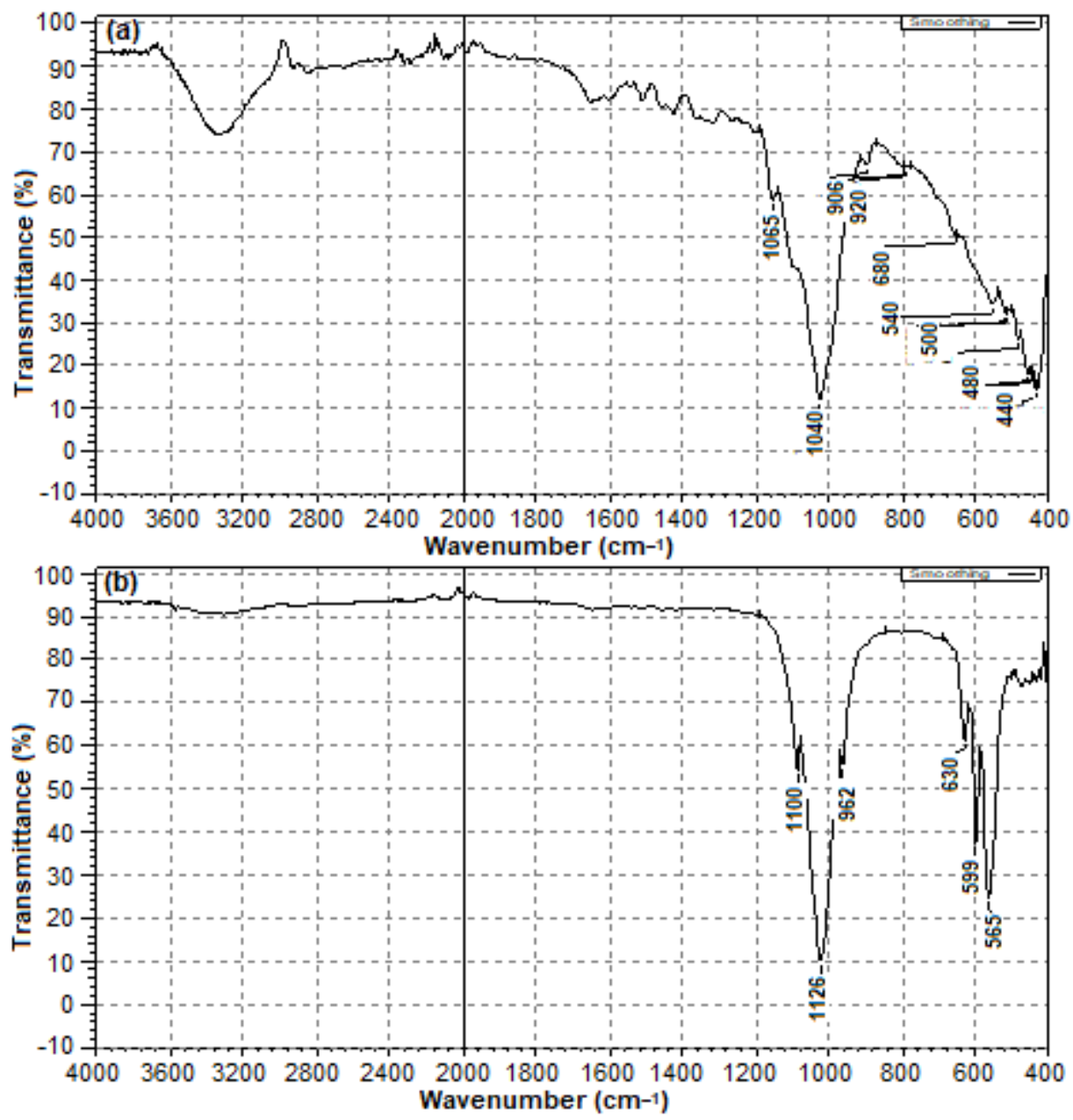

Fig 6. ATR-FTIR spectrum of (a) RH and (b) RH/HAp 


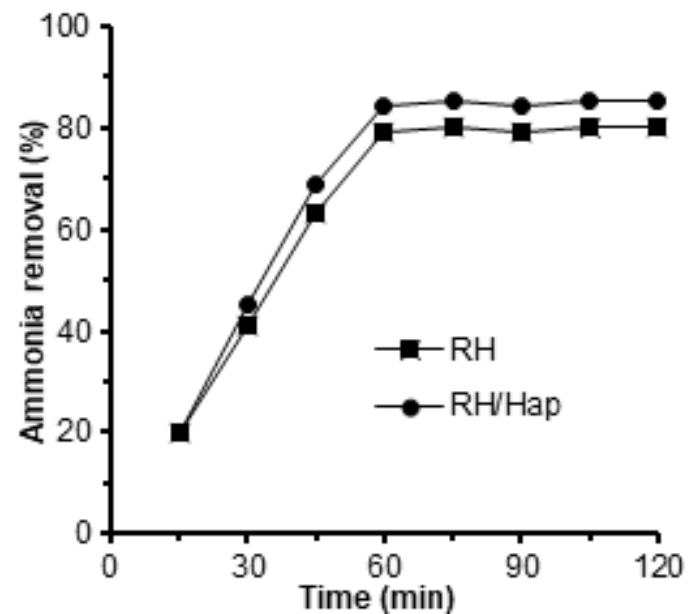

Fig 7. Ammonia removal using (a) RH and (b) RH/HAp (Adsorption condition: RT, dosage $1.5 \mathrm{~g} / \mathrm{L}, \mathrm{pH} 6$ )

result was also obtained since the rice husk itself also has a high capability for ammonia removal and there is an only slight increase of ammonia removal when $\mathrm{RH}$ has integrated with HAp (around 6\% increment). However, it is proved that HAp can be used as coating material for $\mathrm{RH}$ performance in removing pollutants such as ammonia in wastewater.

\section{- CONCLUSION}

In this present study, hydroxyapatite was successfully prepared by using alkaline heat treatment, microwave irradiation, and thermal decomposition method. Characterization of these three types of HAp proof that different method produces different crystallinity level of HAp when different final calcination and different chemical used. Overall results proved that extracted HAp using thermal treatment has maximum performance when it was successfully removed ammonia for about $84 \%$ at saturation time $210 \mathrm{~min}$. The integration of HAp with rice husk shown a better performance when the adsorbent (RH/HAp) was successfully removed ammonia for about $84 \%$ at shorter contact time (60 min). Assembly of HAp as a coating material for rice husk was also a good way to reduce the usage of the high amount of pure HAp as an adsorbent.

\section{- ACKNOWLEDGMENTS}

The authors wish to thank FRGS grant (Vote: 59354) for the fundings of these research and School of Ocean
Engineering, Universiti Malaysia Terengganu for contribution and supports.

\section{- REFERENCES}

[1] Randall, D.J., and Tsui, T.K.N., 2002, Ammonia toxicity in fish, Mar. Pollut. Bull., 45 (1-12), 17-23.

[2] Shao, Y., Shi, Y., Mohammed, A., and Liu, Y., 2017, Wastewater ammonia removal using an integrated fixed-film activated sludge-sequencing batch biofilm reactor (IFAS-SBR): Comparison of suspended flocs and attached biofilm, Int. Biodeterior. Biodegrad., $116,38-47$.

[3] Liu, W., Qian, G., Zhang, B., Liu, L., and Liu, H., 2016, Facile synthesis of spherical nanohydroxyapatite and its application in photocatalytic degradation of methyl orange dye under UV irradiation, Mater. Lett., 178, 15-17.

[4] Sukaimi, J., Hamzah, S., Ali, N., and Ghazali, M.S.M., 2015, Study on adsorption behavior of alkaline protease on poly (ether sulfone) integrated with fish scale hydroxyapatite as self organized in ion exchange membrane, Malays. Appl. Biol., 44 (3), 49-54.

[5] Kongsri, S., Janpradit, K., Buapa, K., Techawongstien, S., and Chanthai, S., 2013, Nanocrystalline hydroxyapatite from fish scale waste: Preparation, characterization, and application for selenium adsorption in aqueous solution, Chem. Eng. J., 215216, 522-532.

[6] Chen, J.D., Wang, Y.J., Wei, K., Zhang, S.H., and Shi, X.T., 2007, Self-organization of hydroxyapatite nanorods through oriented attachment, Biomaterials, 28 (14), 2275-2280.

[7] Barakat, N.A.M., Khil, M.S., Omran, A.M., Sheikh, F.A., and Kim, H.Y., 2009, Extraction of pure natural hydroxyapatite from the bovine bones biowaste by three different methods, J. Mater. Process. Technol., 209 (7), 3408-3415.

[8] Kusunoki, M., Kawakami, Y., Matsuda, T., Nishikawa, H., Hayami, T., and Hontsu, S., 2010. Fabrication of a large hydroxyapatite sheet, Appl. Phys Express, 3 (10), 107003.

[9] Sivakumar, M, Kumar, T.S.S., Shanta, K.L, and Rao, K.P., 1996, Development of hydroxyapatite derived 
from Indian coral, Biomaterials, 17 (17), 1709-1714.

[10] Mondal, S., Mondal, B., Dey, A., and Mukhopadhyay, S.S., 2012, Studies on processing and characterization of hydroxyapatite biomaterials from different biowastes, J. Miner. Mater. Charact. Eng., 11 (1), 5567.

[11] Abidi, S.S.A., and Murtaza, Q., 2014, Synthesis and characterization of nano-hydroxyapatite powder using wet chemical precipitation reaction, J. Mater. Sci. Technol., 30 (4), 307-310.

[12] Li, J., Shirosaki, Y., Hayakawa, S., Stamboulis, A., and Osaka, A., 2013, Sol-gel preparation of HAp-coated silica macrospheres from water glass and their protein adsorption, Key Eng. Mater., 529-530, 637-640.

[13] Mobasherpour, I., Heshajin, M.S., Kazemzadeh, A., and Zakeri, M., 2007, Synthesis of nanocrystalline hydroxyapatite by using precipitation method, $J$. Alloys Compd., 430 (1-2), 330-333.

[14] Shavandi, A, Bekhit A.E.-D.A., Ali, A., and Sun, Z., 2015, Synthesis of nano-hydroxyapatite (nHA) from waste mussel shells using a rapid microwave method, Mater. Chem. Phys., 149-150, 607-616.

[15] Bahrololoom, M.E., Javidi, M., Javadpour, S., and Ma, J., 2009, Characterisation of natural hydroxyapatite extracted from bovine cortical bone ash, J. Ceram. Process. Res., 10 (2), 129-138.

[16] Gumisiriza, R., Mshandete, A.M., Rubindamayugi, M.S.T., Kansiime, F., and Kivaisi, A.K., 2009, Nile perch fish processing waste along Lake Victoria in East Africa: Auditing and characterization, Afr. J. Environ. Sci. Technol., 3 (1), 013-020.

[17] Kousalya, G.N., Gandhi, M.R., and Meenakshi, S., 2010, Removal of toxic $\mathrm{Cr}(\mathrm{VI})$ ions from aqueous solution using nano-hydroxyapatite-based chitin and chitosan hybrid composites, Adsorpt. Sci. Technol., 28 (1), 49-64.

[18] Pham, T.T.T., Nguyen, T.P., Pham, T.N., Vu, T.P., Tran, D.L., Thai, H., and Dinh, T.M.T., 2013, Impact of physical and chemical parameters on the hydroxyapatite nanopowder synthesized by the chemical precipitation method, Adv. Nat. Sci.: Nanosci. Nanotechnol., 4 (3), 035014.
[19] Abdal-Hay, A., Barakat, N.A.M., and Lim, J.K., 2013, Hydroxyapatite-doped poly(lactic acid) porous film coating for enhanced bioactivity and corrosion behavior of AZ31 Mg alloy for orthopedic applications, Ceram. Int., 39 (1), 183-195.

[20] Madhavi, S., Ferraris, C., and White, T.J., 2005, Synthesis and crystallization of macroporous hydroxyapatite, J. Solid State Chem., 178 (9), 28382845.

[21] Singh, A., 2012, Hydroxyapatite, a biomaterial: Its chemical synthesis, characterization and study of biocompatibility prepared from the shell of a garden snail, Helix aspersa, Bull. Mater. Sci., 35 (6), 1031-1038.

[22] Chen, X., Kong, H., Wu, D., Wang, X., and Lin, Y., 2009, Phosphate removal and recovery through crystallization of hydroxyapatite using xonotlite as a seed crystal, J. Environ Sci., 21 (5), 575-580.

[23] Venkatesan, J., and Kim, S.K., 2010, Effect of temperature on isolation and characterization of hydroxyapatite from tuna (Thunnus obesus) bone, Materials, 3 (10), 4761-4772.

[24] Coelho, J.M., Moreira, J.A., Almeida, A., and Monteiro, F.J., 2010, Synthesis and characterization of HAp nanorods from a cationic surfactant template method, J. Mater. Sci. Mater. Med., 21 (9), 2543-2549.

[25] Sarig, S., and Kahana, F., 2002, Rapid formation of nanocrystalline apatite, J. Cryst. Growth, 237-239, 55-59.

[26] López-Ramón, V., Moreno-Castilla, C., RiveraUtrilla, J., and Radovic, L.R., 2003, Ionic strength effects in aqueous phase adsorption of metal ions on activated carbons, Carbon, 41 (10), 2020-2022.

[27] Lin, L., Yuan, S., Chen, J., Xu, Z., and Lu, X., 2009, Removal of ammonia nitrogen in wastewater by microwave radiation, J. Hazard. Mater., 161 (2-3), 1063-1068.

[28] Huang, Y.C., Hsiao, P.C., and Chai, H.J., 2011, Hydroxyapatite extracted from fish scale: Effects on MG63 osteoblast-like cells, Ceram. Int., 37 (6), 1825-1831. 
[29] Al-Hashimi, M.A.I., and Al-Safar, M.M., 2013, Removal of cadmium from synthetic water by using agricultural wastes, Acta Technica CorviniensisBulletin of Engineering, 6 (2), 131-138.

[30] Mourabet, M., El Rhilassi, A., El Boujaady, H., Bennani-Ziatni, M., El Hamri, R., and Taitai, A., 2015, Removal of fluoride from aqueous solution by adsorption on hydroxyapatite (HAp) using response surface methodology, J. Saudi Chem. Soc., 19 (6) 603615.

[31] El Haddad, M., Mamouni, R., Saffaj, N., and Lazar, S., 2012, Removal of a cationic dye -Basic Red 12from aqueous solutions by adsorption onto animal bone meal, J. Assoc. Arab Univ. Basic Appl. Sci., 12
(1), 48-54.

[32] Joseph, C., 2011, The sorption of chemical and nuclear contaminants from soil and water using nanosize particles of hydroxyapatite, Thesis, Missouri University of Science and Technology, 81.

[33] Sharma, Y.C., and Upadhyay, S.N., 2011, An economically viable removal of methylene blue by adsorption on activated carbon prepared from rice husk, Can. J. Chem. Eng., 89 (2), 377-383.

[34] Panda, N.N., Pramanik, K., and Sukla, L.B., 2014, Extraction and characterization of biocompatible hydroxyapatite from fresh water fish scales for tissue engineering scaffold, Bioprocess. Biosyst. Eng., 37 (3), 433-440. 